\title{
Simulation of Competition for Light in Even-Aged Stands of Douglas Fir
}

\author{
C.P. VAN GERWEN, C.J.T. SPITTERS ${ }^{1}$ and G.M.J. MOHREN \\ Department of Theoretical Production Ecology, Agricultural University, P.O. Box 430,6700 AK \\ Wageningen (The Netherlands)
}

'Present address: Foundation for Agricultural Plant Breeding, SVP, P.O. Box 117, 6700 AC

Wageningen (The Netherlands)

(Accepted 15 July 1986)

\begin{abstract}
Van Gerwen, C.P., Spitters, C.J.T. and Mohren, G.M.J., 1987. Simulation of competition for light in even-aged stands of Douglas fir. For. Ecol. Manage., 18: 135-152.

Three versions of an explanatory model to simulate competition between trees within forest stands are presented, based on the distribution of photosynthetically active radiation (PAR) over the trees in the stand. From the amount of PAR absorbed, the rates of assimilation and volume increment are calculated for the trees, which are presented in size classes. Volume increments calculated this way for periods of 35-45 years are compared with measurements from permanent field plots to evaluate different versions of the model.

In the first elementary version of the model, it is assumed that the foliage of all trees is distributed uniformly over the field area, neglecting any differences in individual tree height. In this case, the growth of each tree is proportional to its share of the total foliage area of the stand and approximately proportional to its size. This model version slightly underestimated the variation in diameters observed in the field plots.

The second version of the model takes into account differences in tree height. As a result of the prior assumption that the foliage of all classes is distributed uniformly over the field area, this model version severely overestimated the shading of short trees by tall neighbours, and the variation in diameters was overestimated as compared to the field data.

The third version of the model accounts for clustering of needles within individual crowns in addition to height differences between the classes. This approach gave the better fit to the field data for normally stocked and for dense stands.
\end{abstract}

\section{INTRODUCTION}

Differences in growth rate among the trees within a single species stand are to a large extent due to differences in competitive status, i.e. in the ability of the individual trees to acquire and use the growth-limiting resources light, water and nutrients. Competitive relations are manipulated by thinning which makes 
room for crown development of the remaining trees, and simulation models for growth and competition of trees within a stand may be useful for the evaluation of alternative thinning practices. If these models are based on the underlying physiological processes of growth and development, they can also improve our understanding of the competition process itself.

Competition in forest stands can be described at several different levels of complexity, e.g. (a) using an average tree size for the whole stand, (b) based on a frequency distribution of tree diameters, or even (c) for individual trees, taking into account the influence of nearest neighbours. At the stand level, the mean size of the trees in relation to age, stocking rate and site quality has been considered to be a measure of the overall intensity of competition within the stand (Curtis, 1970). Comparison of the mean tree size within a stand with the sizes recommended for comparable situations, as given in yield tables (e.g. La Bastide and Faber (1972) for The Netherlands), indicates whether and to what extent thinning is required. At the level of frequency distributions, stand structure has been characterized by the distribution of the tree diameters at breast height $(\mathrm{DBH})$, which is commonly used as it is the main parameter measured in the field. The distribution can be represented by discrete classes or by some standard distribution function. The competitive status of each class can then be characterized by its average tree diameter, its height, or its basal area, relative to that of either the mean of the stand or the largest class (Alder and Schneider, 1979). At the individual tree level, the competitive status of a tree has been defined using various descriptions of crown overlap with adjacent trees (review by Ottorini, 1978). Competitive status has also been described by a horizontal zone of influence represented by a polygon that depends on the size of the subject tree in relation to its neighbours (Mead, 1966; Moore et al., 1973; Faber, 1983). These competition indices are mainly descriptive and do not explain or provide an understanding of the competition phenomena. Here we present a model that estimates growth differences between trees from the underlying physiological processes as absorption of photosynthetically active radiation (further referred to as light absorption) and $\mathrm{CO}_{2}$ assimilation.

In the model, annual net increment of the stand is calculated from weather conditions, photosynthetic performance of the foliage, respiration losses, and litter fall, using the approach described by Mohren et al. (1984). Annual increment is allocated to the individual trees according to their share in the assimilation rate of the whole canopy. The trees are grouped into 20 size classes, based on their stem diameter; the model is a frequency-distribution model. To calculate the share of each diameter class in total stand assimilation, three approaches will be used. In the elementary version of the model, total needle area is assumed to be distributed homogeneously within the canopy volume. In the second version, allowance is made for differences in tree height. In the third version, concentration of needle area within the tree crowns is also taken into account. In an explanatory model, the description of competition should 
be derived from the main growth-limiting resource. Here, it is assumed that the light absorption is more important in determining the growth differences among the trees than is competition for water or nutrients.

After a description of the model structure, the three model versions will be evaluated against data of three permanent field plots of Douglas fir (Pseudotsuga mensiezii (Mirb.) Franco). The relative importance of individual tree characteristics in determining the competitive status will be evaluated in a sensitivity analysis of the performance of the three model versions in different hypothetical stands. The model uses time steps of 1 year and is written in CSMP (IBM, 1975).

\section{SIMULATION MODEL}

\section{General structure}

In the model, annual stand growth is calculated and subsequently allotted to the trees according to their estimated share in total stand assimilation.

Total stand growth. The calculation of the total annual increment is summarized below; a detailed description is given by Mohren et al. (1984). Potential gross canopy assimilation of a closed stand of Douglas fir growing under optimum conditions was calculated from the amount of incident light and the photosynthetic characteristics of the species, and amounts to about $48 \times 10^{3} \mathrm{~kg}$ $\mathrm{CH}_{2} \mathrm{O} \mathrm{ha}^{-1}$ year ${ }^{-1}$ for The Netherlands. This amount of carbohydrates $\left(\mathrm{CH}_{2} \mathrm{O}\right)$ is distributed over needles, branches, stems and roots. For each of these biomass components, the annual net dry weight increment is obtained as:

$P_{j}=\mathrm{DWC}\left(\mathrm{DC}_{j} \mathrm{GPP}-R_{j}\right)-L_{j}$

where $P_{j}$ is net annual dry weight increment of component $j\left(\mathrm{~kg} \mathrm{ha}^{-1}\right.$ year $\left.^{-1}\right)$, $\mathrm{DWC}$ dry weight conversion ( $\mathrm{kg}$ dry weight per $\mathrm{kg} \mathrm{CH}_{2} \mathrm{O}$ ), $\mathrm{DC}_{j}$ distribution coefficient for carbohydrates; GPP gross canopy assimilation ( $\mathrm{kg} \mathrm{CH}_{2} \mathrm{O}$ ha ${ }^{-1}$ year $\left.{ }^{-1}\right), R_{j}$ maintenance respiration of component $j\left(\mathrm{~kg} \mathrm{CH}_{2} \mathrm{O}_{2}\right.$ ha $^{-1}$ year $\left.{ }^{-1}\right)$, and $L_{j}$ litter loss of component $j\left(\mathrm{~kg} \mathrm{ha}^{-1}\right.$ year $\left.^{-1}\right)$. Typical values of these variables are given by Mohren et al. (1984). Stem dry weight increment has to be converted to bole volume increment by taking into account the dry weight per unit of fresh volume. Potential canopy assimilation is adjusted for incomplete soil cover multiplication with the degree of canopy closure and for site quality by multiplication with a site reduction factor based on dominant height (Mohren et al., 1984). Thus, stocking degree and site index are accounted for.

Stand structure. The representation of the stand in size classes is based on 20 percentile classes of the cumulative frequency distribution. Each class contains $5 \%$ of the total number of trees, with the class diameter corresponding to 
the median. Thinning is simulated by removing trees, at the same ages and from the same part of the diameter frequency distribution as in the field data sets, together with corresponding amounts of stem, needle, branch and root biomass. Crowns are assumed to be cone-shaped, with dimensions estimated for each tree from its $\mathrm{DBH}$. Tree height is estimated using the relation between tree height and $\mathrm{DBH}$ as observed in the field. Crown radius is calculated as a function of $\mathrm{DBH}$ and stand density using the data of Schneider and Kreysa (1981). Crown length is estimated from crown radius and the ratio crown length:crown radius, which is assumed to decline from 4 at an age of 10 , to 1 at an age of 100 years.

Distribution of total stand growth over the trees. Total stand growth is distributed among the trees according to their share in total assimilation. This depends on the amounts of light absorbed in combination with the efficiency with which this is used for dry matter production. The latter is determined by the assimilation-light response curve for individual leaves. For a given age it is assumed that all trees have equal assimilate distribution over the tree organs, regardless of their competitive status.

In the three model versions mentioned, the spatial arrangement of the needle surface area is treated at different levels of complexity. All three versions will be discussed in detail in the next sections.

\section{Version I: a homogeneous canopy with tree height differences neglected}

Light absorption of a tree is closely related to its foliage area. If the effect of height differences between trees can be neglected, the share of a tree in wholestand light absorption and assimilation is directly proportional to its leaf area index:

$\mathrm{GPP}_{i} / \mathrm{GPP}_{\mathrm{t}}=\mathrm{LAI}_{i} / \mathrm{LAI}_{\mathrm{t}}$

where LAI is leaf area index (ha foliage area per ha ground area); subscripts $i$ and $t$ refer to tree $i$ and the total stand, respectively. LAI is obtained by multiplying needle biomass by the specific needle area. A specific needle area of 0.85 ha needle area (one sided) per $10^{3} \mathrm{~kg}$ needle dry weight (Del Rio and Berg, 1979) was used in the simulations, although recent measurements indicate that a value of 0.65 would be more realistic for Douglas fir (Mohren, 1987).

If the distribution pattern of assimilates is the same for all trees, as is assumed in the simulations, the distribution of needle area over the trees is comparable to the distribution of stem volumes. The share of each tree in the total stem volume of the stand then becomes a convenient measure of the distribution of the current stand increment among the trees. 
Version II: a horizontally homogeneous canopy with trees differing in height

An approach similar to that presented by Spitters and Aerts (1983) for annual vegetation is employed here, in which tall trees capture more light per unit foliage area compared to shorter neighbours and show a higher growth rate per unit foliage area due to the differences in height. To account for this, the canopy is stratified into horizontal layers, and the assimilation of the tree in a layer is again calculated from foliage area and average light absorption in each canopy layer. Summation over the canopy layer yields total assimilation per tree, which is used as the distribution factor for the annual stand increment.

Incident light flux at top of canopy. The model operates with time steps of 1 year. For the calculation of the assimilation rate, average light conditions during the growing season above the canopy must be estimated. Using an average value for incident radiation in $\mathrm{J} \mathrm{ha}^{-1} \mathrm{~h}^{-1}$, annual canopy assimilation can be estimated as average assimilation rate in $\mathrm{kg} \mathrm{ha}^{-1} \mathrm{~h}^{-1} \times$ daylength $\times$ days in the growing season. Using a growing season of 200 days (1 April-17 October) with a total amount of incoming photosynthetic active radiation of $14.6 \times 10^{12}$ $\mathrm{J} \mathrm{ha}^{-1}$ during this period (KNMI, 1961-1979), an average effective daylength (effective: solar altitude more than $8^{\circ}$; Goudriaan and Van Laar, 1978) of 12.5 h, together with a canopy reflection of $4 \%$ for PAR (Jarvis et al., 1976), results in an average flux of PAR that is available for absorption of $5.6 \times 10^{9} \mathrm{~J} \mathrm{ha}^{-1} \mathrm{~h}^{-1}$, or about $150 \mathrm{~W} \mathrm{~m}^{-2}$.

Light profile within the canopy. Light interception by leaves or needles approximately results in an exponential decrease in light intensity with increasing canopy depth. The light intensity beneath a leaf area index $\mathrm{LAI}_{h}$, can be described with:

$I_{h}=I_{0} \exp \left(-k \mathrm{LAI}_{h}\right)$

where $I_{h}$ is the light flux at height $h$ in the canopy $\left(\mathrm{J} \mathrm{ha}^{-1} \mathrm{~h}^{-1}\right), I_{0}$ the light flux available for absorption at the top of the canopy $\left(J \mathrm{ha}^{-1} \mathrm{~h}^{-1}\right), k$ the extinction coefficient, and $\mathrm{LAI}_{h}$ the leaf area index reckoned from the top to height $h$.

The extinction coefficient $k$ is assumed to decrease linearly from 0.8 at stand establishment to 0.4 at an age of 100 years to account for the increasing clustering of needles around branches with age (Oker-Blom and Kellomäki, 1983). Light interception by stems and branches is not explicity accounted for. The light absorption by a layer $z$ follows from the difference between the light intensities at the top and the bottom of the layer, which is derived from equation (3) as:

$I_{\text {abs }, z}=I_{z-1}-I_{z}=I_{z-1}\left(1-\exp \left(-k \mathrm{LAI}_{z}\right)\right)$ 
with $I_{\text {abs }, z}$ absorbed light flux in layer $z\left(\mathrm{~J} \mathrm{ha}^{-1} \mathrm{~h}^{-1}\right), I_{z}$ light flux at the bottom of layer $z\left(\mathrm{~J} \mathrm{ha}^{-1} \mathrm{~h}^{-1}\right)$, and $\mathrm{LAI}_{z}$ leaf area index of layer $z$.

Distribution of needle area with tree height. To calculate the light absorption of a tree in the various canopy layers, the distribution of needle area with tree height must be characterized for each tree. For many species, a parabolic distribution of needle area with height is a good approximation. This appears to hold also for Douglas fir, as is demonstrated by the data of Kinerson and Fritschen (1971).

Assimilation rate. The assimilation rates of the trees are calculated from the assimilation-light response of a single leaf layer. In the model, average values for the needle surface within a layer for the day and for the growing season are used. In that case, the response curve is best approximated by substituting the average light flux into a rectangular hyperbola (Spitters, 1986):

$A=A_{\mathrm{m}} \epsilon I /\left(\epsilon I+A_{\mathrm{m}}\right)$

where $A$ is assimilation rate $\left(\mathrm{kg} \mathrm{CO}_{2} \mathrm{ha}^{-1}\right.$ foliage $\left.\mathrm{h}^{-1}\right), A_{\mathrm{m}}$ assimilation rate of needles at light saturation ( $\mathrm{kg} \mathrm{CO}_{2} \mathrm{ha}^{-1}$ foliage $\left.\mathrm{h}^{-1}\right), \epsilon$ light use efficiency at low light intensity $\left(\mathrm{kg} \mathrm{CO}_{2} \mathrm{~J}^{-1}\right)$, and $I$ absorbed amount of light ( $\mathrm{J}$ ha ${ }^{-1}$ foliage $\mathrm{h}^{-1}$ ). For $A_{\mathrm{m}}$ a value of $15 \mathrm{~kg} \mathrm{CO}_{2} \mathrm{ha}^{-1} \mathrm{~h}^{-1}$ was used (Larcher, 1980; Mohren, 1987), and for $\epsilon$ a value of $12.5 \times 10^{-9} \mathrm{~kg} \mathrm{CO}_{2} \mathrm{~J}^{-1}$ was used (at $20^{\circ} \mathrm{C}$; Ehleringer and Pearcy, 1983). Using the average amount of light absorbed per unit foliage area in layer $z$ ( $I_{\mathrm{abs}, z}$ in equation 4 , divided by the total leaf area index of that layer) gives the assimilation rate per unit foliage area. Summation over the needle area in the canopy layers gives the total assimilation rate of the tree. Applying equation (1) to account for respiration losses and litter fall subsequently gives the net annual increment.

\section{Version III: a discontinuous, clustered canopy with trees differing in height}

The previous versions both assume a homogeneous distribution of the needle area of the different trees within the horizontal plane. In a forest stand, however, the needle area of the trees is concentrated within crowns. Compared to a homogeneous canopy, this implies that total light absorption is smaller as light penetrates through gaps between the crowns, and that short trees receive more light because only part of the tall neighbours' foliage shades the crown of a short tree, if there is any shading at all.

The effects of concentration of needles within crowns are approximated in the third version of the model. This is done by considering the crowns as solid structures, and estimating the gaps between them in terms of horizontal canopy closure. Using the fraction closed, the flux intercepted by the crowns, as well as the flux that passes between the crowns, can be calculated from the flux 


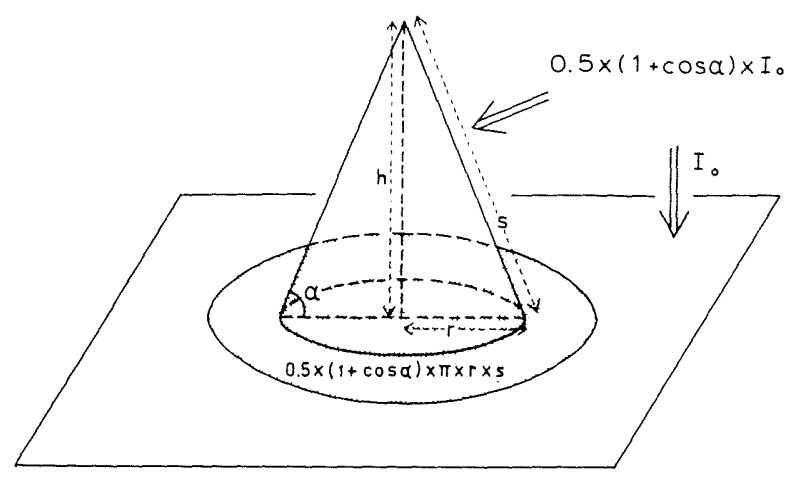

Fig. 1. Cone-shaped crown, characterized by height $h$, radius $r$, slant side $s$ and angle $\alpha$ of mantle with horizontal plane. Under a uniform overcast sky, the illumination intensity on the mantle is $0.5(1+\cos \alpha)$ times that on a horizontal plane. Light interception by the cone is equivalent to that of a projection on the horizontal plane with an area of $0.5(1+\cos \alpha) \pi r s$, where $\pi r s$ is the mantle area of the cone.

at the top of the canopy. Subsequently, this flux is partly absorbed by the crowns and partly transmitted. The fraction absorbed depends on the foliage area within the crown together with its degree of clustering and angular distribution. Computation of light absorption and assimilation per tree proceeds further as in the previous version (II) of the model. This approach to calculate light asorption in relation to crown shape is related to that of Jackson and Palmer (1979) for an apple orchard and has the advantage of being straightforward and simple. It suffices here to use an elementary approach as the main emphasis is on simulation of competition between trees, described in terms of relative growth differences between them, instead of on an exact description of the light climate.

Light interception by cone-shaped crowns. Under a uniform overcast sky, the irradiance into a plane making an angle $\alpha$ with the horizontal is $0.5(1+\cos \alpha)$ times the irradiance on the horizontal plane. All parts of a cone mantle make the same angle with the horizontal, and the light interception of an isolated non-transmitting cone-shaped crown can be found by multiplication of the illumination intensity of the mantle $\left(I_{0} \times 0.5(1+\cos \alpha)\right.$ by the mantle area of the cone $(\pi r s)$, with $\alpha$ representing the inclination of the crown mantle, $r$ radius at the base of the cone $(\mathrm{m})$, and $s$ slant side of the vertical cone section (m) (Fig. 1).

Trees within a stand may cast shadows on each other. As a consequence of this, the light interception of an individual crown is smaller than when growing free. This reduction in light interception is taken into account by estimating the degree of mutual shading. Representing this degree of shading as a factor $\left(f_{\mathrm{sh}}\right)$ the light interception of a stand of solid, identical crowns at a stocking level of $N$ trees ha ${ }^{-1}$ can be expressed as: 


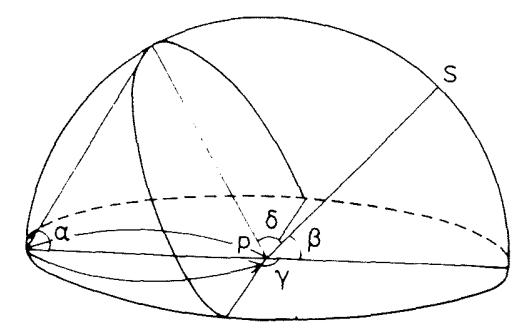

Fig. 2. Point $\mathrm{P}$ on a cone mantle receiving light from a point $\mathrm{S}$ of the hemisphere. PS is set to unity, $\alpha$ inclination of the mantle, $\beta$ elevation of $\mathrm{S}$ above the horizontal level of $\mathrm{P}, \delta$ angle between $\mathrm{S}$ and the tangent plane in $\mathrm{P}$ of the cone mantle, and $\gamma$ ' the difference in azimuth between point $\mathrm{S}$ and the tangent plane in $\mathrm{P}$ of the cone mantle.

$I_{\text {int }}=I_{0} \times 0.5(1+\cos \alpha)(\pi r s) N\left(1-f_{\mathrm{sh}}\right)$

The ratio $I_{\text {int }} / I_{0}$ measures the degree of canopy closure (CC). This can be seen as the projection of the cones onto a horizontal plane receiving the same quantity of light as the cone mantles (shaded area in Fig. 1). Thus $1-\mathrm{CC}$ is the fraction of the incident flux that passes between crowns.

Shading of the crown mantle. Mutual shading of crowns implies that neighbour trees cover a part of the hemisphere otherwise seen by a point on the crown mantle of a central tree. To quantify the shading factor, consider the contribution of a point, $\mathrm{S}$, on the hemisphere to the irradiance onto a point $\mathrm{P}$, in a crown mantle. This contribution is (Goudriaan, 1977, pp. 6, 9; Fig. 2):

$I_{\mathrm{s}} / I_{\mathrm{p}}=\sin \delta \cos \beta=\sin \beta \cos \beta \cos \alpha+\sin \alpha \sin \gamma \cos ^{2} \beta$

where $I_{\mathrm{s}}$ is incoming light flux at a point, $\mathrm{P}$, on the cone mantle, from point $\mathrm{S}$ on the hemisphere; $I_{\mathrm{p}}$ incoming total light flux at a point $\mathrm{P}$ of the cone mantle; $\delta$ angle between $\mathrm{S}$ and the tangent plane of the cone mantle at $\mathrm{P} ; \beta$ elevation of $\mathrm{S}$ above the horizon; $\gamma$ difference between the azimuth of $\mathrm{S}$ and the tangent plane of the cone mantle at $\mathrm{P}$.

For point $\mathrm{P}$ on the cone mantle, the part of the hemisphere covered by a nontransmitting neighbour is seen as a sphere triangle. The reduction in the irradiance onto $\mathrm{P}$ caused by the presence of a neighbour can be calculated by numerical integration of the expression for $I_{\mathrm{s}} / I_{\mathrm{p}}$ (eq. 7) over the sphere triangle. A point on the crown mantle can be shaded by more than one neighbour, and the same procedure is applied for each of them, assuming the trees to be arranged in an equilateral triangle spacing. In the calculation, both first- and second-order trees are taken into account. Essentially, the fraction shaded should be estimated for each part of the crown mantle, and integrated to give the total shading of the tree. This is approximated here from the average reduction in illumination for each height, at point $\mathrm{A}$ in Fig. 3, weighted by the cir- 


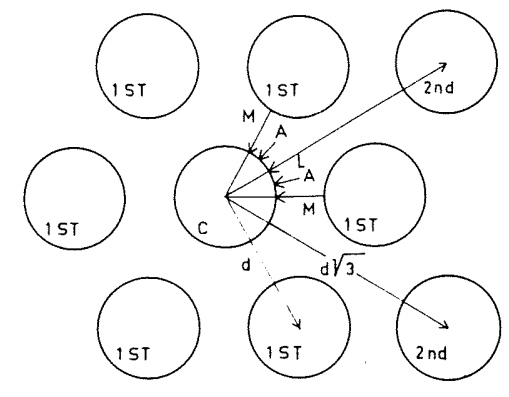

Fig. 3. Trees arranged in a lattice of equilateral triangles, with the central tree $\mathrm{C}$ surrounded by first- and second-order neighbours at distances of $d$ and $d \sqrt{3}$, respectively. Point $\mathrm{M}$ is the most shaded point of the circumference of $\mathrm{C}$ point $\mathrm{L}$ the least shaded point, and $\mathrm{A}$ is the point with average shading.

cumference of the cone. Illumination at $\mathrm{A}$ is considered to represent the average for the mantle circumference at a certain height. This yields the reduction in illumination intensity, both by inclination of the crown mantle $(1-0.5(1+\cos$ $\alpha))$ and by the presence of first- and second-order neighbours $\left(f_{\mathrm{sh}}\right)$. Equation (6) gives the amount of light intercepted $\left(I_{\text {int }}\right)$, from which the degree of canopy closure can be calculated as $I_{\text {int }} / I_{0}$.

Light absorption. So far, crowns have been assumed to be non-transmitting. In a stand part of the light flux falling onto the crowns is transmitted and part is absorbed. This can be calculated using equation (4). Care must be taken in the use of LAI, in that this should refer to the closed canopy part only ( $\mathrm{LAI}=S_{1} W_{\mathrm{f}} / \mathrm{CC}$, with $S_{1}$ equal to specific leaf area in ha $\mathrm{kg}^{-1}, W_{\mathrm{f}}$ foliage weight in $\mathrm{kg} \mathrm{ha}^{-1}$, and $\mathrm{CC}$ canopy closure, equal to $I_{\text {int }} / I_{0}$, equation 6 ). Taking into account different degrees of horizontal canopy closure in relation to height, and calculating light absorption for each canopy layer, light absorption per tree can be estimated. The degree of canopy closure at height $z, \mathrm{CC}_{z}$, is computed, taking into account only those parts of the crowns that protrude above this layer. The flux intercepted by layer $z$ is partitioned into a component that passed between crowns and is transmitted directly to layer $z$ ( $I_{1, z}$ in Fig. 4) and the complement that is transmitted through crowns ( $I_{2, z}$ in Fig. 4). The degree of canopy closure of the layer just above $z\left(\mathrm{CC}_{z-1}\right)$ measures that part of the flux has been intercepted by crown mantle area above $z$, layer $z$ itself intercepts a fraction $\mathrm{CC}_{z}-\mathrm{CC}_{z-1}$. The flux intercepted by layer $z-1\left(I_{\mathrm{int}, z-1}\right)$ is not completely absorbed, but partly transmitted to $z$, depending on the leaf area index in layer $z-1$. In summary, the flux entering the crowns in layer $z$ is:

$I_{\text {int }, z}=I_{1, z}+I_{2, z}=I_{0}\left(\mathrm{CC}_{z}-\mathrm{CC}_{z-1}\right)+I_{\text {int }, z-1} \exp \left(-k \mathrm{LAI}_{z-1}\right)$

where $I_{1, z}$ is flux entering layer $z$ as a fraction of the flux has been transmitted 


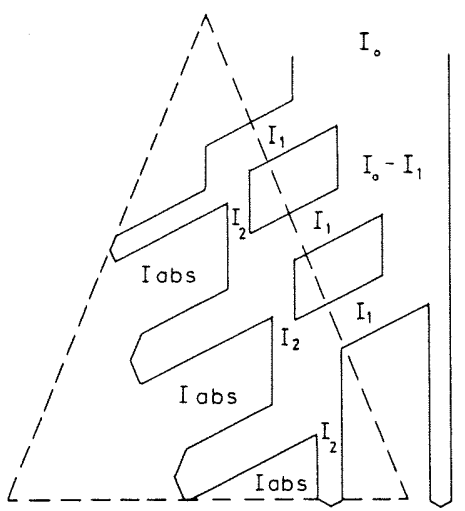

Fig. 4. Distribution of light within a stand of cone-shaped crowns. The incident light flux $\left(I_{0}\right)$ is either intercepted by crowns $\left(I_{1}\right)$ or directly transmitted between crowns $\left(I_{0}-I_{1}\right)$. The intercepted flux is either absorbed $\left(I_{\text {abs }}\right)$ or transmitted through the crowns $\left(I_{2}\right)$. In this example, the canopy is divided into 3 layers.

between the crowns to layer $z$, and $I_{2, z}$ flux entering layer $z$ that has been transmitted through crowns above layer $z$. The absorption can again be estimated from equation (4), with $I_{\text {int.z }}$ for $I_{z-1}$, and with $\mathrm{LAI}_{z}$ again referring to the closed part of the layer only.

The light flux absorbed by a layer is distributed among the trees with needles present in that layer. For tree $i$, light absorption in layer $z$ is calculated as:

$I_{\mathrm{abs}, i, z}=\frac{I_{\mathrm{abs}, z} M_{i, z}\left(1-\exp \left(-k \operatorname{LAI}_{i, z}\right)\right)}{\sum_{j=1}^{N_{z}}\left(M_{j, z}\left(1-\exp \left(-k \operatorname{LAI}_{j, z}\right)\right)\right)}$

where $I_{\text {abs. } i, z}$ is light flux absorbed by layer $z$ of tree $i\left(\mathrm{~J} \mathrm{ha}^{-1} \mathrm{~h}^{-1}\right), M_{i, z}$ mantle area of the cone section of layer $z$ in tree $i$ (ha); $\operatorname{LAI}_{i, 1}$ leaf area of index of tree $i$ in layer $z$ ( ha foliage ha ${ }^{-1}$ shaded ground area); $N_{z}$ number of crowns present in layer $z\left(\mathrm{ha}^{-1}\right)$. The mantle area of the cone section of tree $i$ in layer $z$ reflects its interception capacity. The assimilation rate of each tree is calculated using the same approach as in the versions I and II from light absorption and assimilation-light response, and by adding the contributions of each layer per tree class.

\section{VALIDATION OF THE MODEL}

Test plots. The model was tested against data from three permanent field plots, situated in the centre of The Netherlands. Plot D12 was planted in 1882 and measured from 1923 to 1970. It occupied a near-optimum site. Plots D5 and D9 were of intermediate site quality. Plot D5 was planted in 1899 and measured from 1923 to 1958, while planting of D9 took place in 1901 and measurements 
were made from 1925 to 1967 . All three stands were thinned according to prevailing Dutch forestry practice, implying moderate thinning from below.

Model input. The model was initialized with the frequency distribution of the stem diameters at the time of the first measurement and changes in the frequency distribution with age were simulated with the three versions of the model. The simulation results for primary production and total stem volume increment have already been discussed by Mohren et al. (1984). As it appeared, the volume increment shortly after canopy closure was slightly underestimated, whereas at later stages it tended to be overestimated. The present paper focuses on the distribution of the total annual increment among the individual trees; to avoid bias due to incorrect simulation of the total increment, observed instead of simulated total annual increment was used in the model. Individualtree assimilation rates, as simulated with each of the three models, were used to distribute this total increment among the trees to simulate the competition process.

Comparison of the performance of the three competition models. The cumulative frequency distributions of diameters, as simulated by the three competition models, are represented in Fig. 5, together with the observed distribution. The slope of the cumulative distributions reflects the variation in diameters in the stand. A steep slope indicates small differences, whereas a flat curve indicates a large variation among trees and suggests great differences in competitive ability. As it was assumed that light was the main growth limiting factor, the optimum site, D12, is discussed first.

Model version I slightly underestimated the observed variation; the slope of the curve is steeper than that for the observed data (Fig. 5c). The distribution of the annual increment of the whole stand among the different trees according to their share in the total needle area ignores differences in height among the trees. Model version II, however, which allows for height differences, magnified the differences far too much. This is a result of the assumption of a homogeneous distribution of the needle area in the horizontal plane; it does not take into account the concentration of needles within the crowns so that the shading of short trees by their taller neighbours is overestimated. Model version III allows for the concentration of needles within crowns. This model version slightly underestimated the observed variation; possible reasons of this phenomenon are discussed in the next subsection. Version III also yields a slightly smaller variation than version I, presumably because of the rather low stocking density in plot D12 - 225 trees ha ${ }^{-1}$ at an age of 40 years. Consequently, mutual shading in this plot is of minor importance, which results in an underestimation of the variation in diameters. For the other two plots, model version I underestimated the observed variation, model version II showed a considerable overestimation, and model version III yielded approximately the right 
distribution (Fig. 5a) or showed only a slight underestimation (Fig. 5b). The larger difference between I and III in these plots, compared to that in plot D12, is a consequence of the greater influence of tree height because of the greater stem density: 825 and 1200 trees per hectare at an age of 40 years in D5 and D9 as against only 225 trees in D12.

In general, model version III showed the best performance in normally stocked and dense stands (D5 and D9), and model versions I in sparse stands (as in D12). The regressions of the cumulative frequency distributions simulated by model version I on the measured distribution had slopes of $0.77,0.53$ and 0.65 for plots D5, D9 and D12, respectively. For version III, the slopes were $1.08,0.78$ and 0.52 , respectively. All simulations accounted for $90 \%$ or more of the observed variation in diameters.

Deviations of the model from the real world system. Some major causes of the discrepancies between simulation results and observations will now be discussed. Model version III serves as reference because it is the most comprehensive of the three.

(a) The simulations were initialized with the diameters of the different trees within the stand. On the basis of this initial variation, differences among the trees in light absorption and growth rate were calculated. In addition to the variation in initial status, there are other reasons why trees differ in growth rate, e.g. environmental heterogeneity within the stand and genetic variation in features such as the pattern of dry matter distribution within the tree. Since the model does not account for these aspects it tends to underestimate the treeto-tree variation in the field. This may be an explanation of the underestimation by model version III in the optimum plot D12 (Fig. 5c).

(b) If the canopy has not yet closed, a relatively isolated tree $i$ will monopolize a greater share of the remaining open space than a tree, $j$, which is closely surrounded by other trees. Thus, by the time the canopy is completely closed, tree $i$ with its greater crown expansion will have occupied a larger part of the total available growing space, so it also will have a higher growth rate in subsequent years. This means that irregular spacing is an additional source of variation in growth rate, possibly causing the model to underestimate the variation. Irregularities in plant arrangement exert their influence mainly through their effects during the stages with incomplete canopy closure, i.e. in the early stages and shortly after thinning operations. Model performance is therefore

Fig. 5. Observed and simulated cumulative frequency distributions for diameter at breast height (DBH) in the field plots D5, D9 and D12. The results refer to an age of 59, 66 and 88 years for D5, D9 and D12, respectively. Model I assumes a homogeneous canopy and thus neglects differences in tree height. Model II accounts for differences in tree height but assumes the canopy to be homogeneous in the horizontal plane: In model III, a discontinuous canopy is assumed with trees differing in height and foliage area clustered within individual crowns. 

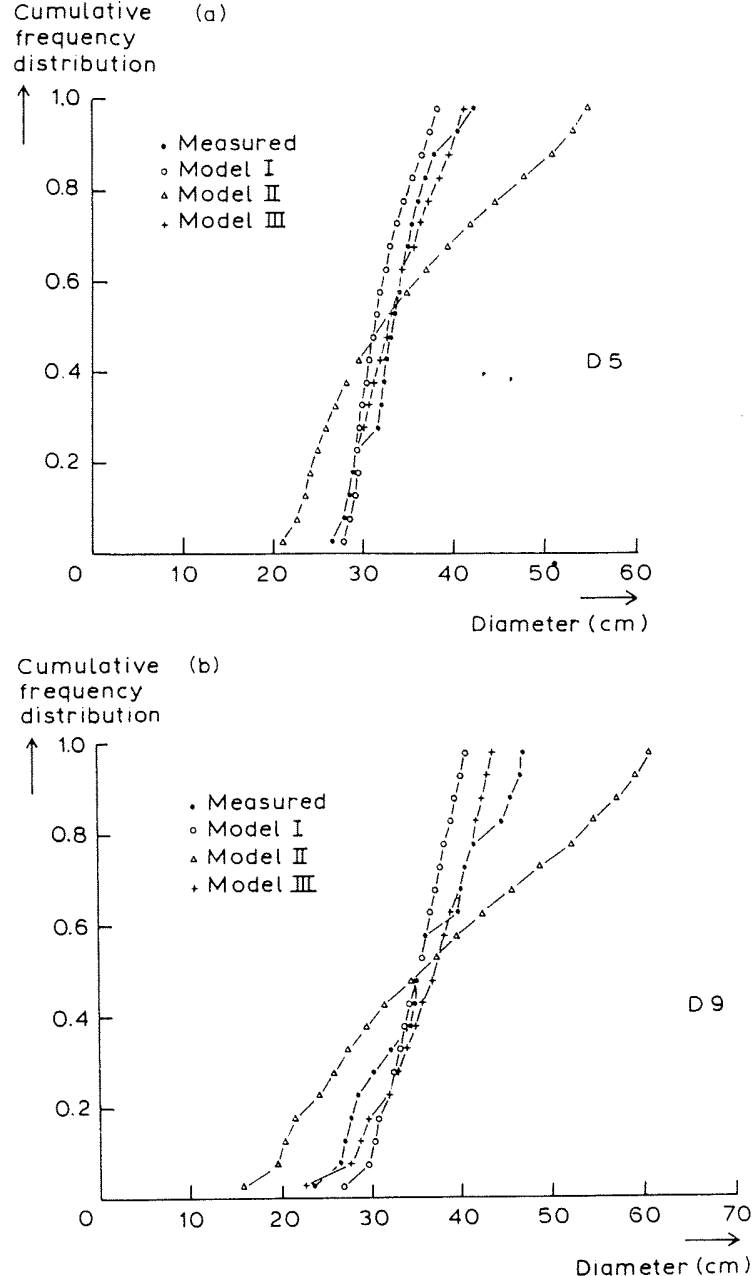

Cumulative

frequency

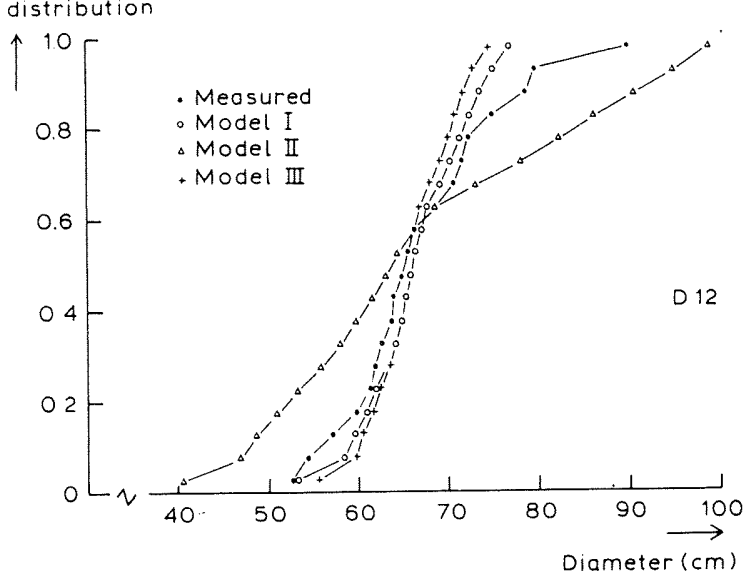


better when initialized with the diameters at canopy closure, rather than with those at planting. When the canopy is closed, spacing will be of minor importance because the available growing space has then been fully occupied, and each tree grows proportional to its share in the total.

(c) Plots D5 and D9 occupy sites with limited water or nutrient supply. In the simulations, however, growth is assumed to be limited only by light. Despite this, the simulation results for plots D5 and D9 are comparable to those for plot D12. Under sub-optimal conditions the share of the trees in total needle area (model version I) apparently still remains a satisfactory distribution function. One reason for this could be that the share of a tree in the total root system will be closely related to its size, and thus to its share in total biomass and needle area. In the absence of differences in dry matter partitioning, this is a valid assumption. Also, the share in the uptake of water and nutrients depends, under conditions of equal availability to all trees, on the demand of a tree for these resources and will therefore be closely related to its total amount of needle area. Leaf area index of a tree, relative to that of the stand, determines the share of a tree in total stand transpiration, and is also correlated with total amount of nutrients to be taken up by the roots. However, the competitive advantage of tallness will be reduced.

Sensitivity analyses. To illustrate the influence of certain tree characteristics on tree photosynthesis in a stand with uniform canopy, a hypothetical stand composed of two size classes was simulated with model version II. In the reference situation, the two classes were assumed to be identical at an overall density of 400 trees $\mathrm{ha}^{-1}$. In each simulation run, a single feature of class 2 was reduced by $20 \%$. Table 1 shows the simulated assimilation rate of class 2 as a fraction of that of class 1 . A reduction in foliage area results in a proportional decrease of assimilation rate (line $b$ in Table 1 ). The effect of a height difference is very pronounced (line $c$ in Table 1 ). This was to be expected because version II ignores the concentration of needles in crowns. In line d of Table 1, crown architecture of class 2 is changed, resulting in a lower light absorption per unit foliage area. This causes a less-than-proportional decrease in photosynthetic rate because the decrease in the degree of light saturation of the needles results in a more efficient use of the captured light. On the other hand, less efficient use of the absorbed light results in a decrease in assimilation rate ( $\mathrm{A}_{\mathrm{m}}$; line e in Table 1 ) or a lower initial light use efficiency ( $\epsilon$; line $\mathrm{f}$ in Table $1)$.

To evaluate the performance of the three model versions in relation to the architecture of the canopy, a hypothetical stand was simulated using model version III (Table 2). A reduction in the foliage area of class 2 to $80 \%$ of that of class 1 reduces the assimilation rate at 800 trees per ha by $17 \%$ (line a in Table 2). A decrease in the number of stems reduces the difference in assimilation rate. Remember that version I takes the ratio of the leaf area indices as 
TABLE 1

Simulated effect of single characteristics on the ratio between the assimilation rates of two tree classes when these classes are grown together in a mixed stand

\begin{tabular}{|c|c|c|c|}
\hline \multirow[t]{2}{*}{ Characteristic } & \multicolumn{2}{|c|}{ Established ratio } & \multirow{2}{*}{$\begin{array}{l}\text { Assimilation } \\
\text { rate } \\
\text { class 2/class } 1\end{array}$} \\
\hline & class 1 & class 2 & \\
\hline a. Reference & & & 1.00 \\
\hline b. Leaf area index & 4.0 & 3.2 & 0.80 \\
\hline c. Tree height $(\mathrm{m})$ & 30 & 24 & 0.18 \\
\hline d. Extinction coefficient & 0.60 & 0.48 & 0.88 \\
\hline e. Max. leaf assimilation $\left(\mathrm{kg} \mathrm{CO}_{2} \mathrm{ha}^{-1} \mathrm{~h}^{-1}\right)$ & 15 & 12 & 0.91 \\
\hline f. Initial light use efficiency $\left(10^{-9} \mathrm{~kg} \mathrm{CO}_{2} \mathrm{~J}^{-1}\right)$ & 11.0 & 8.8 & 0.88 \\
\hline
\end{tabular}

The starting point is stand of two identical classes (line a). In each of the other lines, only the characteristic mentioned is reduced, for class 2 , to a value of $80 \%$ of that for class 1 . The simulations are based on model II which assumes a homogeneous distribution of foliage area in the horizontal plane. The reference situation is thought to be typical for a stand age of 50 years and is based on a density of 400 trees ha $^{-1}$ with an average crown length of $8.7 \mathrm{~m}$.

the ratio of the assimilation rates of the classes, in this case 0.8 . In this analysis, model version III predicts less variation in tree assimilation than version I, and this difference is less important in open stands. The effect of height difference simulated with version II (Table 1 , line c) is much more pronounced than estimated with version III ( Table 2 , line b, with 400 trees $^{-1} \mathrm{a}^{-1}$ ), because of the simulated concentration of needles in crowns. A reduction in crown radius of class 2 results in a reduction of light interception by that class. More-

\section{TABLE 2}

Simulated effect of single characteristics on the ratio between the assimilation rates of two tree classes when these classes are grown together in a mixed stand at three different densities

\begin{tabular}{|c|c|c|c|c|c|}
\hline & \multicolumn{2}{|c|}{ Established ratio } & \multicolumn{3}{|c|}{$\begin{array}{l}\text { Assimilation rate class } 2 / \text { class } 1 \\
\text { Trees per ha }\end{array}$} \\
\hline & class 1 & class 2 & 150 & 400 & 800 \\
\hline a. Leaf area index & 4.0 & 3.2 & 0.87 & 0.84 & 0.83 \\
\hline b. Tree height $(\mathrm{m})$ & 30 & 24 & 0.91 & 0.54 & 0.24 \\
\hline c. Crown radius $(\mathrm{m})$ & 3.2 & 2.6 & 0.90 & 0.94 & 0.96 \\
\hline
\end{tabular}

The classes are identical except that in each line the characteristic mentioned was reduced, for class 2 , to a value of $80 \%$ of that for class 1 . The simulations are based on model III, which accounts for the arrangement of the needle areas within individual crowns. The results at 400 trees ha ${ }^{-1}$ are similar to those of model II (Table 1). Crown length is held constant in modifying tree height and crown radius. 
over, the needles of class 2 are more concentrated, resulting in increased internal shading. The overall effect is a reduction of the assimilation rate of class 2 , even though it has as large a needle area as class 1 (line c in Table 2).

\section{CONCLUSIONS}

Of the three versions of the competition model presented, version III gave the best fit with respect to the variation in stem diameter observed in normally stocked and in dense stands of Douglas fir (plots D5 and D9; Fig. 5a, b). In this model version, allowance is made for concentration of needle area within individual crowns with the crowns differing in height. It provides an elementary description of the distribution of light in the canopy layer. Model version I distributes the total increment among the trees proportional to their needle area and does not account for differences in tree height. As a consequence, this model tends to underestimate the observed variation in stem diameter when competition through mutual shading is important. Its simplicity, however, means that it may be useful as a first approximation. This holds especially for short-term predictions as in that case competition relations are mainly determined by initial conditions. Neglecting differences among trees in their drymatter allocation pattern simplifies model I to an approach where whole-stand increment is distributed among the trees according to their size, e.g. measured by their stemwood volume. This implies that percentage differences among trees are then maintained in time.

Model version II, which takes into account the variation in tree height but not the concentration of needle area within individual crowns, considerably overestimated the competition effects (Fig. 5). Although it performs well for annual stands (Spitters and Aerts, 1983; Spitters, 1984), it can not be used in forest stands, as their concentration of needle area within separate crowns thereby reduces competition for light to border conflicts between neighbouring crowns. This situation necessitates a more comprehensive competition model as model version III.

\section{ACKNOWLEDGEMENTS}

The data were supplied by the Growth and Yield Department of the Institute for Forestry and Landscape Planning 'De Dorschkamp' at Wageningen. The authors wish to thank Dr. J. Goudriaan for valuable comments during the development of the model and Mr. B.J. van Amersfoort and Mrs. C.G. Uithol for typing versions of the manuscript.

\section{REFERENCES}

Alder, D. and Schneider, T.W., 1979. A stand growth model as a tool in studying management options for $\mathrm{MAB}$ - rainforest ecosystem projects and for temperate forests. In: S. Adisoemarto 
and E.F. Brünig (Editors), Trans. Second Int. MAB-IUFRO Workshop on Tropical Rainforest Ecosystems Research, 21-25 October, 1978, Jakarta. Hamburg-Reinbek, Chair of World Forestry, Special Rep., 2: 128-165.

Curtis, R.O., 1970. Stand density measures: an interpretation. For. Sci, 16: 403-414.

Del Rio, E. and Berg, A., 1979. Specific leaf area of Douglas-fir reproduction as affected by light and needle age. For. Sci., 25: 183-186.

Ehleringer, J. and Pearcy, R.W., 1983. Variation in quantum yield for $\mathrm{CO}_{2}$ uptake among $\mathrm{C}_{3}$ and $\mathrm{C}_{4}$ plants. Plant Physiol., 73: 555-559.

Faber, P.J., 1983. Competition and growth of trees within a forest stand. Uitvoerig verslag 18(1), Institute for Forestry and Lanscape Planning 'De Dorschkamp', Wageningen, 116 pp. (in Dutch, with English summary).

Goudriaan, J., 1977. Crop micrometeorology: a simulation study. Simulation Monograph, Pudoc, Wageningen, $249 \mathrm{pp}$.

Goudriaan, J. and Van Laar, H.H., 1978. Calculation of daily totals of the gross $\mathrm{CO}_{2}$ assimilation of leaf canopies. Neth. J. Agric. Sci., 26: 373-382.

IBM, 1975. Continuous System Modelling Program III (CSMP III), Program Reference Manual. IBM SH19-7001-3, Technical Publications Department, White Plains, NY, 206 pp.

Jackson, J.E. and Palmer, J.W., 1979. A simple model of light transmission and interception by discontinuous canopies. Ann. Bot., 44: 381-383.

Jarvis, P.G., James, G.B. and Landsberg, J.J., 1976. Conferous forest. In: J.L. Monteith (Editor), Vegetation and Atmosphere. Vol. 2: Case Studies. Academic Press, London, pp. 171-239.

Kinerson, R.S. and Fritschen, L.J., 1971. Modelling a conferous forest canopy. Agric. Meteorol., 8: $439-445$.

KNMI, 1961-1979. Monthly survey of weather conditions. Koninklijk Meteorologisch Instituut, De Bilt, The Netherlands (In Dutch).

La Bastide, J.G.A. and Faber, P.J., 1972. Revised yield tables for six tree species in The Netherlands. Uitvoerig verslag 11(1), Forestry Research Institute 'De Dorschkamp', Wageningen, $64+36 \mathrm{pp}$.

Larcher, W., 1980. Physiological Plant Ecology (2nd revised Edition). Springer, Berlin, 303 pp.

Mead, R., 1966. A relationship between individual plant spacing and yield. Ann. Bot., 30: 301-309.

Mohren, G.M.J., 1987. Simulation of forest growth, applied to Douglas fir stands in the Netherlands. Doctoral diss., Agricultural Univ., Wageningen, The Netherlands, 184 pp.

Mohren, G.M.J., Van Gerwen, C.P. and Spitters, C.J.T., 1984. Simulation or primary production in even-aged stands of Douglas fir. For. Ecol. Manage., 9: 27-49.

Moore, J.A., Budelsky, C.A. and Schlesinger, R.C., 1973. A new index representing individual tree competitive status. Can. J. For. Res., 3: 495-500.

Oker-Blom, P. and Kellomäki, S., 1983. Effect of grouping of foliage on the within-stand and within-crown light regime: comparison of random and grouping canopy models. Agric. Meteorol., 28: 143-155.

Ottorini, J.M., 1978. Density measures for tree growth studies in forest stands. Ann. Sci. For., 35: 299-320 (In French).

Peat, W.E., 1970. Relationships between photosynthesis and light intensity in the tomato. Ann. Bot., 34: 319-328.

Schneider, T.W. and Kreysa, J., 1981. Dynamische Waschstums- und Ertragsmodelle für die Douglasie und die Kiefer. Mitt. Bundesforschungsanst. Forst- und Holzwirtsch., 135, Hamburg-Reinbek, $137 \mathrm{pp}$.

Spitters, C.J.T., 1984. A simple simulation model for crop-weed competition. COLUMA-EWRS, 7th Symp. Weed Biology, Ecology and Systematics, Paris, pp. 355-366.

Spitters, C.J.T., 1986. Separating the diffuse and direct component of global radiation and its implications for modelling canopy photosynthesis. II. Calculation of canopy photosynthesis. Agric. For. Meteorol. (In press). 
Spitters, C.J.T. and Aerts, R., 1983. Influence of environmental factors on herbicide performance and crop and weed biology. Aspects Appl. Biol., 4: 467-483. 